Revista Destaques Acadêmicos, Lajeado, v. 12, n. 2, 2020. ISSN 2176-3070

DOI: http://dx.doi.org/10.22410/issn.2176-3070.v12i2a2020.2255

http://www.univates.br/revistas

\title{
A EVOLUÇÃO HISTÓRICA DO ESTADO E O DIREITO INTERNACIONAL: COORDENAÇÃO OU SUBORDINAÇÃO?
}

\begin{abstract}
Alana Petry ${ }^{1}$
Resumo: $\mathrm{O}$ direito internacional público tem sua origem atribuída à assinatura dos tratados de paz de Westfália, em 1648, quando foi reconhecida a igualdade soberana dos Estados. Nesse sentido, o presente artigo tem como objetivo investigar se a igualdade soberana dos Estados existe de fato e se o direito internacional público cumpre com a sua função de estabelecer uma relação de coordenação no âmbito das relações internacionais. A pesquisa é qualitativa, desenvolvida por meio de método dedutivo e de procedimento técnico bibliográfico e documental. No decorrer do trabalho, analisa-se a evolução histórica do Estado e, posteriormente, o surgimento do direito internacional público. Por fim, investiga-se, adotando-se a teoria realista, a (in) existência da igualdade soberana dos Estados e se o direito internacional público é um sistema de coordenação ou de subordinação dos membros da sociedade internacional. Conclui-se que é possível verificar que o princípio da igualdade soberana é uma ficção jurídica e que o direito internacional público está muito distante de cumprir com sua finalidade, pois funciona como um instrumento de poder e subordinação utilizado pelos Estados mais poderosos.
\end{abstract}

Palavras-chave: Estado. Igualdade soberana. Direito internacional público. Coordenação. Subordinação.

\section{INTRODUÇÃO}

O conceito de Estado relaciona-se com a ideia de uma organização política que, através de um poder soberano, delimita um território e institui um sistema de normas jurídicas que visa a regular as relações entre os indivíduos que integram aquela sociedade. Para que uma organização possa ser considerada um Estado ela deve apresentar elementos essenciais, isto é, território, povo e governo soberano.

Ao longo do tempo, a organização estatal evoluiu, assumindo diferentes formas em cada período histórico. Assim como o Estado, o direito também

1 Diplomada do curso de Direito da Universidade do Vale do Taquari - Univates, apetry@universo.univates.br. 
foi se transformando, tanto o direito interno, que visa a regular as relações entre os particulares e sujeitos nacionais, quanto o direito internacional, que é responsável por coordenar as relações entre os sujeitos internacionais, compreendidos os Estados, indivíduos e organismos de âmbito internacional.

Em sua maioria, a doutrina estabelece como marco de origem do direito internacional público a assinatura dos tratados de paz de Westfália, em 1648. Nesse momento, foi reconhecida a igualdade soberana de todos os Estados, princípio fundamental do direito internacional público, que objetiva garantir equilíbrio nas relações internacionais e a observância da soberania estatal de cada país.

Nesse sentido, o presente artigo discutirá como problema se o direito internacional público é verdadeiramente um sistema de normas jurídicas que busca estabelecer uma relação de coordenação entre os membros da comunidade internacional. $\mathrm{O}$ objetivo geral será investigar se a igualdade soberana dos Estados existe de fato e se o direito internacional público garante que todos os países tenham competências e espaços de ação igualitários.

Como hipótese para o problema, acredita-se que a igualdade soberana é uma ficção jurídica criada com a finalidade de garantir a hegemonia de determinados países, que detêm poder suficiente para fazer com que suas decisões prevaleçam sobre as opiniões ou necessidades dos demais países, de acordo com as premissas da teoria realista. Ademais, supõe-se que o direito internacional público não é um sistema de coordenação, mas de subordinação, uma vez que se verifica que existe prevalência de interesses dos Estados mais poderosos.

Quanto ao modo de abordagem, a pesquisa será qualitativa, realizada através de método dedutivo e por meio de procedimento técnico bibliográfico e documental. Para alcançar o objetivo proposto, a primeira parte do artigo analisará a evolução histórica do Estado. Em uma segunda parte, se pesquisará o advento do direito internacional público. Na última parte, será investigada a (in)existência da igualdade soberana dos Estados e se o direito internacional público é um sistema de coordenação ou de subordinação dos membros da sociedade internacional.

Ante o exposto, pensa-se na relevância da pesquisa a ser desenvolvida, pois possibilitará a reflexão sobre a finalidade do direito internacional na modernidade, bem como a discussão acerca do modo como ele vem sendo utilizado, enquanto instrumento de controle e poder, como ramo do direito que é. Outrossim, oportunizará a análise sobre a (in)existência do princípio da igualdade soberana dos Estados.

\section{A EVOLUÇÃO HISTÓRICA DO ESTADO}

Antes de a comunidade internacional eleger o termo Estado como designação de uma unidade político-jurídica, outras expressões eram 
utilizadas para denominar um ente estatal. $\mathrm{O}$ termo foi usado pela primeira vez por Maquiavel, no século XVI, em seu livro “O Príncipe" (DALLARI, 2014), substituindo as expressões utilizadas até então, como, por exemplo, principado e república (RANIERI, 2013).

Nesse sentido, embora o termo Estado tenha surgido no século XVI, é somente a partir do Estado Liberal, primeira modalidade do Estado de Direito, surgido entre os séculos XVIII e XIX, que a expressão passou a ser adotada para representar o sentido que possui atualmente, conforme explicam Gorczevski e Konrad (2013).

Menciona-se que alguns estudiosos utilizam o nome Estado para conceituar as diferentes formas estatais que existiram ao longo da história, desde as mais remotas até às organizações modernas, enquanto outros empregam a expressão apenas para indicar os entes estatais que surgiram após o Estado Medieval, pois acreditam que o conceito surgiu para denominar uma realidade completamente nova e "uma forma de ordenamento tão diverso dos ordenamentos precedentes que não podia mais ser chamado com os antigos nomes" (BOBBIO, 2007, p. 67).

De acordo com Ranieri (2013, p. 12), hodiernamente o Estado pode ser considerado como "uma forma específica de sociedade política, organizada mediante regras e dotada de poder superior sobre os seus membros", que possui personalidade jurídica interna e internacional. Sendo assim, é possível afirmar que o Estado é a representação de uma ordem jurídica que se impõe sobre todos, existindo um verdadeiro direito de subordinação que deve ser observado pelos indivíduos.

Ao longo do tempo, a organização estatal precisou evoluir para atender às necessidades do corpo social, que foi se tornando cada vez mais complexo. Destarte, a primeira forma estatal é denominada de Estado Antigo, na qual não existia uma divisão entre o Estado e a religião, posto que "a autoridade do governo e as normas de comportamento eram tidas como expressão de um poder divino" (STRECK; MORAIS, 2006, p. 23).

Em seguida, cita-se a existência do Estado Grego e o Estado Romano, que organizavam-se tendo como base a existência das Cidades-Estado, caracterizadas pela independência, autonomia e economia autossuficiente. No entanto, ambos consideravam como povo apenas uma pequena parcela da população (STRECK; MORAIS, 2006), uma vez que a noção de democracia era bastante seletiva, excluindo do exercício da cidadania mulheres, escravos e estrangeiros.

Durante a Idade Média, emerge o Estado Medieval, caracterizado principalmente pela influência do cristianismo e da Igreja Católica, esta última almejando a criação de um Império Cristão, e pelo feudalismo, sistema baseado na posse de terra e na situação patrimonial. Nessa perspectiva, Dallari (2014, p. 77) explica que a forma medieval de Estado apresentava: 
[...] um poder superior, exercido pelo Imperador, com uma infinita pluralidade de poderes menores, sem hierarquia definida; uma incontável multiplicidade de ordens jurídicas [...]. Esse quadro [...], era causa e consequência de uma permanente instabilidade política, econômica e social, gerando uma intensa necessidade de ordem e de autoridade, que seria o germe de criação do Estado Moderno.

Nasce, então, o Estado Moderno "no início do século XVI, ao final da Idade Média, sobre as ruínas do feudalismo" (BARROSO, 2019, p. 36), objetivando corrigir as falhas do Estado Medieval e, sobretudo, alcançar a unidade estatal. Para isso, afirma-se detentor de um poder soberano, modifica o modelo de dominação, que passa a ser a dominação legal-racional, substitui o direito consuetudinário pelo direito produzido pela autoridade estatal através da lei e promove uma separação entre os poderes público e privado.

A primeira versão assumida pelo Estado Moderno foi o Estado Absolutista, no qual o poder soberano se concentrava exclusivamente na pessoa do monarca. Esse modelo estatal atendeu durante muito tempo aos propósitos da classe burguesa, entretanto, no limiar do século XVIII, a burguesia desejava ter, além do poder econômico, também o controle do poder político (STRECK; MORAIS, 2006).

Assim, com o objetivo de limitar, através da lei, o poder absoluto do soberano e de organizar as funções do Estado, a classe burguesa assume o poder político e conduz ao surgimento de um novo modelo de organização estatal. Inspirada nos ideais liberais difundidos com a Revolução Francesa em 1789 (HOBSBAWM, 2012) e na crença das virtudes da razão (DALLARI, 2014), a burguesia acaba provocando "a decadência do Estado absolutista e a emergência do Estado de Direito" (CORTUCCI, 2015, p. 281).

O movimento revolucionário conduzido pela burguesia acarreta a ruína da hegemonia do sistema feudal e da autoridade divina, "vindo à tona a teoria do contrato social, que vislumbra o homem como centro da teoria política, e o Estado resultado de um pacto firmado entre os homens livres e iguais" (GORCZEVSKI; KONRAD, 2013, p. 71). Dessa forma, o Estado de Direito tem como um de seus fundamentos a ideia da primazia da lei sobre os poderes das autoridades, buscando também promover os direitos individuais e as liberdades públicas.

O Estado Liberal, que surge entre os séculos XVIII e XIX, é a primeira versão do Estado de Direito, tendo como escopo a garantia da liberdade, da propriedade e da segurança e como princípios o individualismo, a democracia e o liberalismo. Seu sustentáculo era a instituição de uma Constituição, "um documento escrito no qual se declaram as liberdades e os direitos e se fixam os limites do poder político" (CORTUCCI, 2015, p. 280).

Nesse modelo estatal, a função do Estado é negativa, restringindo-se apenas a garantir o exercício dos direitos individuais. Ocorre que a abstenção 
do ente estatal, somada à crise enfrentada pelo capitalismo, foram responsáveis por produzir inúmeras desigualdades, fazendo com que fosse necessária a intervenção estatal (CORTUCCI, 2015). Logo, o Estado passa a desempenhar ações positivas, preocupando-se com a "denominada genericamente questão social, envolvendo os temas mediata e imediatamente relacionados ao processo produtivo" (STRECK; MORAIS, 2006, p. 78).

Essas são as características do Estado Social, terceira versão do Estado Moderno e segunda modalidade do Estado de Direito, que desejava minimizar os problemas surgidos com o modelo de produção capitalista, garantir o bemestar da população, ampliar a igualdade em sentido material e promover um maior equilíbrio nas relações sociais.

Todavia, a questão da igualdade material não foi solucionada e, por esse motivo, entre outros, se desenvolve um novo conceito de Estado, o Estado Democrático de Direito, em meados do século XX, resultando do constitucionalismo que emergiu internacionalmente após a Segunda Guerra Mundial (STRECK; MORAIS, 2006). Nesse modelo estatal, a dignidade da pessoa humana é elevada à categoria de princípio geral e fundamental e a lei passa a exercer a função de mecanismo transformador da realidade.

Nesse sentido, "quando assume o feitio democrático, o Estado de Direito tem como objetivo a igualdade e, assim, não lhe basta limitação ou a promoção da atuação estatal, mas referenda a pretensão à transformação do status quo" (STRECK; MORAIS, 2006, p. 100). Por isso, o Estado Democrático de Direito representa uma junção dos dois modelos de Estado de Direito anteriores, buscando conciliar e efetivar, por intermédio de ações concretas e da garantia de condições mínimas de vida, a liberdade, a igualdade e a democracia, suprindo as lacunas das modalidades antecedentes.

Portanto, verifica-se que cada novo modelo de organização estatal representa uma ruptura com o modelo anterior, além de representar um avanço, pois as transformações ocorrem com a finalidade de melhorar as condições sociais, bem como adequar o modelo de Estado ao momento histórico, social, político e econômico. Acompanhando a evolução histórica do Estado, o direito e a ordem jurídica, igualmente, se modificam, não só internamente como também a nível internacional. Assim, cabe analisar o surgimento do direito internacional e os fatores que resultaram na criação de um ordenamento responsável por regular as relações entre os países.

\section{O SURGIMENTO DO DIREITO INTERNACIONAL PÚBLICO}

Enquanto o direito interno de um país busca regular as relações privadas entre os indivíduos e as relações dos indivíduos com o Poder Público, o direito internacional público visa a coordenar as relações entre os Estados e a comunidade internacional. Nessa lógica, Buis $(2015$, p. 5) explica que "podemos 
definir al derecho internacional público como un sistema de normas jurídicas que regulan las relaciones entre los sujetos de la comunidad internacional".

Majoritariamente, os estudiosos afirmam que o marco de origem do direito internacional foi a assinatura dos tratados de Paz de Westfália, em 1648. Conforme Dallari (2014), esses tratados documentam a criação do Estado Moderno e o reconhecimento dos seus limites territoriais e do exercício exclusivo do poder dentro de seu território. Em suma, proclamam a igualdade soberana dos Estados. Varella (2016, p. 21) esclarece:

Trata-se de um ramo do direito que nasce na Idade Média, com a própria formação do Estado, mas que ganha importância a partir da consolidação dos Estados europeus e a expansão ultramarina. Cresce com a maior interdependência global, no século XX, e sofre uma expansão importante, sobretudo, a partir dos anos noventa. Como o próprio mundo moderno, o direito internacional é um ramo do direito em constante transformação. É um dos ramos do direito que mais sofre transformações nos últimos anos.

É possível verificar a existência do direito internacional desde a Antiguidade Clássica, quando as Cidades-Estado gregas e romanas realizavam negociações e acordos com outras Cidades-Estado, buscando regular as relações comerciais e econômicas (BUIS, 2011). Assim, esse ramo do direito foi acompanhando o desenvolvimento e a evolução das formas estatais, surgindo para atender a necessidade de um conjunto de normas que regulassem as relações internacionais entre países e cidades.

Primeiramente, o direito internacional se restringiu a acordos e convênios de natureza comercial e econômica. Porém, com o passar do tempo, "la comunidad de Estados fue permitiendo una progresiva ampliación de las temáticas cometidas a negociación en el plano internacional" (BUIS, p. 9, 2015).

Em razão do aumento da complexidade das relações internacionais, da ocorrência das duas grandes guerras mundiais e da criação da Organização das Nações Unidas (ONU), passaram a ser discutidos temas que ainda não haviam sido regulados de modo adequado, como "derechos humanos, derecho ambiental, derecho internacional penal, derecho comercial internacional, derecho del espacio ultraterrestre, etc" (BUIS, 2015, p. 17), bem como técnicas de cooperação internacional e assuntos relativos a questões humanitárias.

Nesse contexto de transformação do direito internacional público, enfatiza-se o processo de internacionalização dos direitos humanos e a criação de um sistema internacional de proteção desses direitos. Para tanto, a noção de soberania estatal foi relativizada, estabelecendo-se limites à vontade soberana e independente dos Estados; a temática dos direitos humanos foi elevada à categoria de matéria de relevância internacional; e o indivíduo passou a ocupar posição de sujeito internacional (PIOVESAN, 2018). Consoante à autora citada, esse cenário transforma "o conceito tradicional que situava o Direito 
Internacional apenas como a lei da comunidade internacional dos Estados e que sustentava ser o Estado o único sujeito de Direito Internacional" (PIOVESAN, 2018, p. 207).

Para entender a atuação dos atores no espaço internacional, é necessária, para além do direito internacional público, a existência de teorias das Relações Internacionais, que "têm a finalidade de formular métodos e conceitos que permitam compreender a natureza e o funcionamento do sistema internacional, bem como explicar os fenômenos mais importantes que moldam a política mundial" (NOGUEIRA; MESSARI, 2005, p. 2). Para Jackson e Sorensen (2007, p. 60), "o núcleo tradicional das RI está relacionado a questões sobre a dinâmica e a mudança da condição do Estado soberano no contexto de um sistema maior ou sociedade de Estados".

De acordo com o afirmado por Buis (2011), o direito internacional público moderno tem como fundamento o princípio da igualdade soberana, que se traduz no reconhecimento de que os entes estatais são iguais em termos jurídicos. Isso significa que todos os Estados, apesar de suas diferenças, se encontram em uma situação idêntica, isto é, sem distinções hierárquicas. Teixeira (2013, p. 117) ressalta que:

A soberania é hoje uma afirmação do Direito Internacional Positivo, muito mais do que uma ideia doutrinária. A Carta da ONU afirma, em seu artigo $2^{\circ}, \S 1^{\circ}$, que a organização 'é baseada no princípio da igualdade soberana de todos os seus membros'. No âmbito regional, a Carta da Organização dos Estados Americanos estatui, no artigo $3^{\circ}$, letra ' $f^{\prime}$ ', que a 'ordem internacional é constituída essencialmente pelo respeito à personalidade, soberania e independência dos Estados'. Toda jurisprudência internacional, compreendida a Corte de Haia, é carregada de afirmações relativas à soberania dos Estados e à igualdade soberana que rege sua convivência.

Essa equiparação entre os membros da comunidade internacional é indispensável para que não haja a prevalência dos interesses dos Estados que detêm maior poder sobre aqueles menos poderosos. Assim, a positivação da igualdade soberana dos Estados visa a criação de uma paridade entre os sujeitos, para que o sistema de normas jurídicas internacionais seja equilibrado, descentralizado e que tenha como base a vontade concorrente de todos os entes estatais (BUIS, 2011).

Diante do exposto, verifica-se que o surgimento do direito internacional público veio ao encontro de uma necessidade da comunidade internacional, que aspirava a criação, com base em um acordo de vontades entre os sujeitos, de um conjunto de normas jurídicas que pudessem regular as relações entre os Estados, garantindo equilíbrio e igualdade entre os distintos membros, bem como promover a proteção internacional dos direitos humanos. 
Contudo, é imperioso questionar se, de fato, o princípio da igualdade soberana pode ser observado na realidade, exercendo sua função de mecanismo de limitação e controle do poder; e se o direito internacional público é verdadeiramente um sistema equilibrado e igualitário, baseado em uma lógica de coordenação.

\section{O PROBLEMA DA SOBERANIA E O DIREITO INTERNACIONAL: COORDENAÇÃO OU SUBORDINAÇÃO}

A soberania é um dos elementos essenciais de uma organização estatal, juntamente com o povo e o território. Isso significa que não basta que o Estado possua um governo, pois é crucial que esse governo seja soberano, sendo superior e exercido sem subordinação a qualquer outro poder. Isto posto, é possível verificar que o Estado detém soberania, porque seu poder é vertical e hierarquizado, uma vez que se impõe sobre os demais poderes.

Segundo Rezek (2018, p. 268-269), a soberania consiste em uma qualidade essencial do Estado, "que o faz titular de competências que, precisamente porque existe uma ordem jurídica internacional, não são ilimitadas; mas nenhuma outra entidade as possui superiores". No entanto, esse elemento estatal também precisa ser encarado sob outra perspectiva:

Se é certo que a soberania, como elemento estatal, contribuiu para a formação e afirmação do Estado tal como o concebemos até os dias de hoje, é verdade também que, à medida em que esse mesmo Estado entra em crise ou, à medida em que o processo decisório do poder deixa de ser um monopólio estatal, passando a ser compartilhado com outros atores e, mais, a noção de Estado nacional perde espaço e até mesmo sentido em tempos de internacionalização do direito e de globalização de valores, pessoas e culturas, o próprio conceito de soberania pode ser questionado e até mesmo relativizado (ASSIS, 2013, p. 27).

Nesse sentido, destacam-se algumas ideias básicas da teoria realista, que são: pessimismo acerca da natureza humana; conflitos como características intrínsecas das relações internacionais; e segurança nacional e sobrevivência estatal como objetivos principais do Estado (JACKSON; SORENSEN (2007, p. 102). Nogueira e Messari (2005, p. 23) também citam algumas premissas do realismo, como a "centralidade do Estado, que tem por objeto central sua sobrevivência, a função do poder para garantir essa sobrevivência, seja de maneira independente [...], seja por meio de alianças, e a resultante anarquia internacional".

Conforme já afirmado, a assinatura dos tratados de Paz de Westfália marcam o surgimento do direito internacional público moderno e o reconhecimento da igualdade soberana. Não obstante, o princípio da igualdade soberana merece ser questionado, uma vez que vem se mostrando desajustado 
da realidade, considerando a atual conjuntura mundial. Nesse sentido, importante as colocações de Buis (2011, p. 77):

[...] el surgimiento del sistema internacional occidental en la consagración de un 'derecho entre iguales' y en el rechazo definitivo de la imposición de cualquier autoridad supra-estatal por sobre la voluntad de los Estados. [...] Pero, ¿en qué sentido se dice que Westfalia representa el momento de 'creación' de un moderno derecho internacional, basado en la coordinación y la cooperación inter pares? Una respuesta fundada no es sencilla. Un análisis estricto de los tratados que componem la Paz de Westfalia (Münster y Osnabrück), sin embargo, demuestra que en rigor de verdad sus textos ocultan una profunda desigualdad entre los firmantes.

Portanto, embora a igualdade soberana seja o princípio capital do direito internacional público, a realidade demonstra que ainda existem muitas desigualdades entre os Estados, pois há, no cenário internacional, uma imposição da vontade dos Estados mais influentes sobre os outros. Assim, a igualdade soberana jurídica e política é apenas aparente, pois as normas internacionais não surgem do diálogo ou da união de vontades concorrentes, mas de imposições dos Estados mais fortes, uma vez que, adotando-se a visão da teoria realista, "as relações interestatais são caracterizadas pela incessante luta pelo poder", exemplificada pela conservação do poder e manutenção do status quo, pela expansão do poder ou pela demonstração do poder (JATOBÁ, 2013, p. 22).

Conforme Buis (2015), até 1648, o modelo que vigorava internacionalmente era o pré-clássico ou modelo realista hipotético, no qual os Estados mais poderosos subordinavam os demais Estados, fazendo prevalecer as suas vontades e impor as regras jurídicas que mais lhe beneficiavam. A partir da Paz de Westfália, surge o modelo do paradigma westfaliano, que se ampara na ideia de "ficción de que los Estados son iguales jurídicamente por gozar de una soberanía exclusiva que no puede ser afectada por el resto de la comunidad internacional" (BUIS, 2015, p. 13).

Apesar da adoção do paradigma westfaliano, indaga-se a respeito da (in) existência do princípio da igualdade soberana dos Estados, visto que a ideia de igualdade entre os entes estatais é refutada pelo notório poderio exercido pelo seleto grupo de países que dita as regras e os rumos do mundo globalizado. No cenário internacional, "a estrutura constrange os Estados a adotar determinados comportamentos, limitando e orientando suas ações por meio de recompensas e penalizações", sendo que "o sistema distribui os benefícios em favor daqueles que são mais poderosos" (JATOBÁ, 2013, p. 30-31). Ainda, é possível refletir se todos os Estados são efetivamente soberanos ou se apenas os membros do seleto grupo mencionado detém o elemento essencial da soberania. 
Nesse contexto, também reflete-se sobre a função exercida pelo direito internacional público na atualidade, que deveria ser fundamentada em um modelo de coordenação e cooperação entre as partes juridicamente iguais, conforme afirmado por Buis (2011). Diferentemente do que se observa no poder do Estado, que subordina o seu povo às normas de direito interno, $\mathrm{o}$ direito internacional não tem o condão de subordinar nenhum membro, pois ele deveria ser formado de acordo com a vontade concorrente de todos os entes estatais.

Todavia, o que se verifica no atual cenário é que o direito internacional público acabou se tornando um modelo de subordinação, tendo em vista a desigualdade entre os seus membros, em razão de questões históricas, políticas e econômicas. Diante disso, verifica-se um desequilíbrio nas relações internacionais e uma disparidade na participação dos Estados no desenvolvimento do direito internacional. Nessa perspectiva, Nogueira e Messari (2005, p. 25) explicam que:

O Estado convive, portanto, com uma dupla realidade: uma interna, em que é soberano e tem a autoridade e a legitimidade de impor decisões e diretrizes, e uma outra realidade externa, em que está ausente qualquer autoridade que tenha a legitimidade de tomar e impor decisões. Nesta segunda realidade, o Estado tem como função principal - para não dizer única - a defesa do interesse nacional, isto é, a preservação e a permanência do Estado como ator nas relações internacionais.

O maior exemplo da desigualdade existente entre os membros da comunidade internacional é representado pela formatação da Organização das Nações Unidas (ONU), que é composta por uma Assembleia Geral, órgão deliberativo integrado por todos os países membros da organização, que possuem direito a um voto (PEREIRA, 2009). O obstáculo da Assembleia Geral é que suas resoluções não possuem caráter vinculante, limitando-se somente a fazer recomendações (BUIS, 2011).

Além da Assembleia Geral, a ONU também possui um Conselho de Segurança, formado por 15 membros, "sendo cinco deles permanentes, que são os Estados responsáveis pela vitória sobre as tropas alemãs na Segunda Guerra Mundial" (PEREIRA, 2009, p. 133), isto é, Estados Unidos, China, Rússia, Reino Unido e França. E os dez outros membros são transitórios, sendo eleitos para mandatos de dois anos. No tocante às votações desse órgão, Piovesan (2018, p. 219) explica:

Cada membro do Conselho de Segurança tem direito a um voto. As deliberações do Conselho em questões processuais são tomadas pelo voto afirmativo de nove membros. Em relação às questões materiais, as deliberações também são tomadas pelo voto afirmativo 
de nove membros, incluindo, todavia, os votos afirmativos de todos os cinco membros permanentes [...]. Dessa previsão é que decorre o poder de veto dos membros permanentes.

A partir da análise da estrutura do Conselho de Segurança, o problema da desigualdade fica evidenciado porque os membros permanentes são detentores exclusivos do direito de veto, "instrumento a través del cual cualquiera de ellos puede impedir que el Consejo de Seguridad tome decisiones, incluso cuando se cuente con el voto afirmativo de los otros catorze integrantes del órgano" (BUIS, 2011, p. 68). Portanto, fica claro que esses Estados exercem um poder maior dentro da organização e também no âmbito internacional, fazendo com que seus interesses sejam beneficiados em prejuízo dos interesses dos demais membros.

Além do poder de veto no âmbito do Conselho de Segurança da ONU, há muitas outras amostras da desigualdade existente entre os membros da comunidade internacional, como, por exemplo, a influência do direito norteamericano e europeu no direito da América Latina. Essa influência é uma das causas da falta de identificação da população com as instituições jurídicas e com o direito escrito, além de prejudicar a posição dos países latino-americanos nas relações jurídicas internacionais (ESQUIROL, 2016).

A concentração do poder empresarial nas mãos de multinacionais norte-americanas ou europeias, sejam elas do ramo do petróleo, da mineração, de alimentos, de veículos ou de tecnologia, é um nítido exemplo do poderio exercido por essas nações. Essas empresas interferem ilimitadamente na economia, no meio ambiente, nas riquezas naturais e no sistema de produção e de trabalho de outros países, muitas vezes com a conivência dos governos locais. Além da conquista territorial-geográfica:

Conquista-se pela imposição da cultura, da economia, da ideologia política, entre outros. A título de exemplo, vê-se imposição de políticas de austeridade pelo Banco Central Mundial a países que não desejam tal medida, músicas, filmes e modo de vida estadunidenses exportados e compartilhados pelos quatro cantos do mundo, necessidade de uma política de mercado alinhada à internacional para a sobrevivência no cenário mundial, entre outras (FACHIN, 2018, p. 264).

Os exemplos mencionados corroboram o entendimento de que há Estados mais poderosos, que utilizam o direito internacional como instrumento para concretizar e proteger seus interesses, como também manter suas posições hegemônicas no cenário internacional. Ressalta-se que "para os realistas, o interesse nacional do Estado é [...] a sobrevivência do Estado e sua permanência como ator" (NOGUEIRA; MESSARI, 2005, p. 27). 
Por isso, a afirmação de Galeano (2013, p. 18) ainda faz tanto sentido nos dias de hoje, embora sua obra se refira apenas à América Latina: "do descobrimento aos nossos dias, tudo sempre se transformou em capital europeu ou, mais tarde, norte-americano, e como tal se acumulou e se acumula nos distantes centros do poder".

Sendo assim, não há dúvidas de que "Westfalia se construyó como un gran mito capaz de sentar las bases de una ficción extremadamente útil para preservar el status quo de las relaciones internacionales" (BUIS, 2011, p. 78). Consoante Nogueira e Messari (2005, p. 29), "nas relações internacionais, o poder é central. Atores se juntam ao poder ou se juntam contra o poder. [...] Estados adotam uma atitude ou outra dependendo de seu interesse nacional". Ainda, os autores complementam "fica claro que a balança (ou equilíbrio) de poder não significa necessariamente que a distribuição do poder seja equilibrada entre os vários Estados" (NOGUEIRA; MESSARI, 2005, p. 29).

Diante do reconhecimento da existência desse problema, é possível afirmar que a declaração da igualdade soberana dos Estados não é suficiente para garantir a efetiva igualdade nas relações internacionais e nem para promover um modelo de direito internacional baseado na coordenação.

\section{CONCLUSÃO}

Com a assinatura dos tratados de paz de Westfália, em 1648, ocorre o surgimento do Estado Moderno, que representa um grande avanço para a sociedade, visto que substitui o Estado Medieval, rompendo com o antigo paradigma estatal, baseado na religião e no feudalismo, e objetivando corrigir as falhas do medievo. Além disso, esse acontecimento histórico também é tido como marco de criação do direito internacional público e do reconhecimento da igualdade soberana dos Estados, princípio expresso no art. $2, \S 1^{\circ}$ da Carta da ONU.

Contudo, a pesquisa desenvolvida possibilitou verificar que, embora a igualdade soberana esteja expressamente declarada na Carta da ONU, essa previsão não garante a sua efetividade, posto que a realidade demonstra que os Estados ainda apresentam muitas diferenças e espaços de ação desiguais no âmbito internacional e dentro da própria ONU. Ademais, através da pesquisa também conclui-se que o direito internacional público não cumpre com a sua função de coordenar as relações internacionais, tendo em vista que ocorre uma subordinação dos países menos poderosos àqueles que detém a hegemonia do poder na atualidade.

Sendo assim, a hipótese inicial se mostrou verdadeira, visto que se verificou, com base no estudo realizado, que a igualdade soberana proclamada em 1648 é uma ficção jurídica, que não leva em consideração as inúmeras desigualdades existentes entre os países e que tem a finalidade de preservar o 
sistema internacional nos moldes em que ele está, garantindo a supremacia dos interesses dos Estados mais fortes.

Portanto, o direito internacional público está muito distante de cumprir com a sua função de possibilitar equilíbrio e coordenação nas relações internacionais, pois acaba servindo aos interesses de determinados Estados e funcionando como instrumento de exercício e controle do poder por esses países, que subordinam os demais membros da comunidade internacional às suas decisões. Dessa maneira, o direito internacional público transforma-se em um sistema de subordinação, no qual verifica-se a hegemonia e o imperialismo de países que detém o exercício do poder há muitas décadas.

Além de ser possível afirmar que a igualdade soberana é um mito jurídico utilizado por determinados países para manter suas posições no cenário internacional, constatou-se que há uma divergência entre a teoria e a prática das relações internacionais, uma vez que o principal objetivo dos Estados que detém a hegemonia do poder é, além de sua sobrevivência, conforme defendido pela teoria realista, também a dominação cada vez maior dos Estados mais fracos.

Sendo assim, para que o direito internacional público cumpra com a sua função, é necessário que a igualdade soberana seja concretizada substancialmente, isto é, exista na realidade, diminuindo-se as desigualdades existentes entre os países e proibindo ações estatais que visem a promover a subordinação de países menos poderosos àqueles que detém o monopólio do poder internacional. Quando isso ocorrer, talvez o direito internacional público se torne um sistema de coordenação, verdadeiramente democrático, que seja utilizado para consolidar a cooperação internacional e solucionar as inúmeras questões humanitárias existentes.

\section{REFERÊNCIAS}

ASSIS, Luiz Gustavo Bambini de. Soberania Estatal: concepção, evolução e desafios do tema para o Estado do século XXI. Revista de Direito Constitucional e Internacional. São Paulo: Revista dos Tribunais, v. 85, p. 13-28, out./dez., 2013. Disponível em: <https://www.revistadostribunais.com.br>. Acesso em: 29 maio 2018.

BARROSO, Luís Roberto. Curso de direito constitucional contemporâneo: os conceitos fundamentais e a construção do novo modelo. 8. ed. São Paulo: Saraiva Educação, 2019. E-book. Disponível em: <http:/ /www.univates.br/biblioteca/ebooks-minha-biblioeca?isbn=9788553610112>. Acesso em: 27 maio 2019.

BOBBIO, Norberto. Estado, governo, sociedade: para uma teoria geral da política. 13. ed. Rio de Janeiro: Paz e Terra, 2007. 
BUIS, Emiliano J. El derecho internacional público: concepto, características y evolución histórica. In: González Napolitano et al. Lecciones del Derecho Internacional Público. Buenos Aires: Errepar, 2015, p. 1-21.

. Sobre gnomos y gigantes: los tratados grecorromanos y la igualdad soberana de los Estados como ficción histórico-jurídica. Lecciones y Ensayos. Buenos Aires, n. 89, 2011, p. 73-117.

ORGANIZAÇÃO DAS NAÇÕES UNIDAS (ONU). Carta das Nações Unidas. 1945. Disponível em: <https:/ / nacoesunidas.org/carta/>. Acesso em: 27 maio 2019.

CHEMIN, Beatris F. Manual da Univates para trabalhos acadêmicos: planejamento, elaboração e apresentação. 3. ed. Lajeado: Univates, 2015. E-book. Disponível em: $<$ www.univates.br/biblioteca>. Acesso em: 25 maio 2019.

CORTUCCI, Andréa Mancine. Neoconstitucionalismo - Apontamentos acerca da nova hermenêutica constitucional no Estado Democrático de Direito. Revista de Direito Constitucional e Internacional. São Paulo: Revista dos Tribunais, v. 92, ano 23, p. 275304, jul./set., 2015.

DALLARI, Dalmo de Abreu. Elementos de teoria geral do Estado. 32. ed. São Paulo: Saraiva, 2014.

ESQUIROL, Jorge L. Ficções do direito latino-americano. Ronaldo Porto Macedo Junior, José Reinaldo de Lima Lopes (Coords.). Coleção teoria e história do direito. São Paulo: Saraiva, 2016. E-book. Disponível em: <http:/ /www.univates.br/biblioteca/ebooks-minha-biblioeca?isbn=9788502631267>. Acesso em: 29 maio 2017.

FACHIN, Jéssica. Obstáculos à cooperação internacional: as instituições internacionais a partir da teoria realista. Revista de Direito Constitucional e Internacional. São Paulo: Revista dos Tribunais, v. 105, p. 259-279, jan./fev., 2018. Disponível em: <https: / / www.revistadostribunais.com.br>. Acesso em: 29 maio 2018.

GALEANO, Eduardo H. As veias abertas da América Latina. Porto Alegre: L\&PM, 2013.

GORCZEVSKI, Clovis; KONRAD, Letícia Regina. Evolução histórica da Jurisdição Constitucional: apontamentos sobre a proteção internacional dos direitos humanos no Estado Democrático de Direito. In: GORCZEVSKI, Clovis; LEAL, Mônia Clarissa Hennig (Orgs.). Constitucionalismo contemporâneo: concretizando direitos. Curitiba: Multideia, 2013, p. 69-87.

HOBSBAWM, Eric J. A era das revoluções: 1789-1848. 25. ed. São Paulo: Paz e Terra, 2012.

JACKSON, Robert; SORENSEN, Georg. Introdução às relações internacionais: teorias e abordagens. Rio de Janeiro: Zahar, 2007. 
JATOBÁ, Daniel. Teoria das Relações Internacionais. Antônio Carlos Lessa, Henrique Altemani de Oliveira (Coords.). São Paulo: Saraiva, 2013. (Temas essenciais em RI, v. 2).

NOGUEIRA, João Pontes; MESSARI, Nizar. Teoria das Relações Internacionais: correntes e debates. Rio de Janeiro: Elsevier, 2005.

PEREIRA, Bruno Yepes. Curso de direito internacional público. 3. ed. São Paulo: Saraiva, 2009. E-book. Disponível em: <http:/ /www.univates.br/biblioteca/e-booksminha-biblioeca?isbn=9788502152694>. Acesso em: 03 dez. 2017.

PIOVESAN, Flávia. Direitos humanos e o direito constitucional internacional. 18. ed. rev. atual. São Paulo: Saraiva Educação: 2018. E-book. Disponível em: <http:/ /www. univates.br/biblioteca / e-books-minha-biblioeca?isbn=9788553600274>. Acesso em: 28 maio 2019.

RANIERI, Nina Beatriz Stocco. Teoria do Estado: do Estado de Direito ao Estado Democrático de Direito. Barueri: Manole, 2013.

REZEK, José Francisco. Direito internacional público: curso elementar. 17. ed. São Paulo: Saraiva, 2018. E-book. Disponível em: <http:/ / www.univates.br/biblioteca/ebooks-minha-biblioeca?isbn=9788553172894> . Acesso em: 26 maio 2019.

STRECK, Lenio Luiz; MORAIS, José Luis Bolzan de. Ciência política e teoria do Estado. 5. ed. rev. atual. Porto Alegre: Livraria do Advogado, 2006.

TEIXEIRA, Carla Noura. Direito internacional para o século XXI. São Paulo: Saraiva, 2013. E-book. Disponível em: <http:/ / www.univates.br/biblioteca/e-books-minhabiblioeca?isbn=9788502183346>. Acesso em: 25 maio 2019.

VARELLA, Marcelo D. Direito internacional público. 7. ed. São Paulo: Saraiva Educação, 2018. E-book. Disponível em: <http:/ / www.univates.br/biblioteca/ebooks-minha-biblioeca?isbn=9788547229344> . Acesso em: 26 maio 2019. 